\title{
Investigation on the interactions of lymphoma cells with paclitaxel by Raman spectroscopy
}

\author{
Duo Lin ${ }^{\mathrm{a}}$, Juqiang Lin ${ }^{\mathrm{a}, *}$, Yanan $\mathrm{Wu}^{\mathrm{b}}$, Shangyuan Feng ${ }^{\mathrm{a}}$, Yongzeng $\mathrm{Li}^{\mathrm{a}}$, Yun $\mathrm{Yu}^{\mathrm{a}}$, \\ Gangqin Xi ${ }^{a}$, Haishan Zeng ${ }^{c}$ and Rong Chen ${ }^{a}$ \\ ${ }^{a}$ Key Laboratory of OptoElectronic Science and Technology for Medicine, Ministry of Education, \\ Fujian Normal University, Fuzhou, Fujian, China \\ ${ }^{\mathrm{b}}$ Fujian Provincial Hospital, Fuzhou, Fujian, China \\ ${ }^{\mathrm{c}}$ Cancer Imaging Department, British Columbia Cancer Research Centre, Vancouver, BC, Canada
}

\begin{abstract}
The single-cell Raman spectra of human Burkitt's lymphoma cells (CA46) including cells treated with different doses of paclitaxel and controls without paclitaxel can be detected by confocal micro-Raman spectroscopy. It shows that the Raman bands at $1094 \mathrm{~cm}^{-1}$ assigned to the symmetric stretching vibration mode of O-P-O in the DNA backbone, $1338 \mathrm{~cm}^{-1}$ and $1578 \mathrm{~cm}^{-1}$ due to adenine and guanine of DNA all decrease in intensity with increasing drug dose. On the contrary, the intensity of peaks at $1257 \mathrm{~cm}^{-1}$ due to characteristic vibration of $\alpha$-helix of Amide III and $1658 \mathrm{~cm}^{-1}$ due to characteristic vibration of $\alpha$-helix of Amide I both increases with increasing drug dose. Multivariate statistical methods, such as Principle Components Analysis (PCA) and Linear Discriminant Analysis (LDA) were employed to discriminate normal lymphoma cells (CA46) and cells treated with different doses of paclitaxel. It was found that the sensitivity and specificity of differentiating the treated and untreated cell groups increase with drug doses and approach $100 \%$ for the high drug dose, consistent with the perception that the cytotoxicity increases with drug dose. These results suggest that Raman spectroscopy combined with multivariate analysis could become a useful tool for assessing the cytotoxicity of drugs such as paclitaxel on human lymphoma cells.
\end{abstract}

Keywords: Raman spectroscopy, paclitaxel, lymphoma, CA46, Principle Components Analysis (PCA), Linear Discriminant Analysis (LDA)

\section{Introduction}

The mechanism of most anti-cancer drugs is that they can disorder biochemical and biophysical intracellular properties to induce apoptosis of the cancer cells. Currently, the investigation of cancer cells treated with anti-cancer drugs in vitro culture has become one of main test methods for the efficacy of anti-cancer drugs. Whereas, monitoring the changes of intracellular properties plays a significant role in this method. Most current pharmacological, histological and cellular techniques, however, are low-

\footnotetext{
*Corresponding author: Dr. Juqiang Lin, Key Laboratory of Optoelectronic Science and Technology for Medicine, Ministry of Education and Fujian Provincial Key Laboratory for Photonics Technology, Fujian Normal University, Fuzhou 350007, China. Tel.: +86 5918348 9919; Fax: +86 5918346 5373; E-mails: jqlin@ fjnu.edu.cn.
} 
specificity, complex procedures, or destruction to cell samples. There is a need for new technology that surmounts these limitations to provide a convenient and accurate method for detection of cancer cells treated with drugs.

Raman spectroscopy, based on the inelastic scattering of photons by molecular bond vibrations, has been used in probing the structure and content changes of biochemical molecules inside tumor cells. The intracellular information about DNA, protein and lipid content as well as conformation can be probed by positions, intensities and line-widths of the various spectral bands. Moreover, this technology is non-destructive, high-sensitive and high-automated [5,9,10,17,20]. Recently, Yao group have applied near-infrared Raman spectroscopy to analyze the apoptosis of single human gastric cancer cells, induced by 5-FU drug during incubation [28].

However, some spectral peaks belong to different compositions of living cells may overlap sometimes, which make it difficult for us to analyze the Raman spectra and extract the useful information about changes of intracellular properties. Therefore, it is not enough accurate and overall to study the changes of biochemical molecules inside tumor cells only depending on the analysis of spectral assignment and the changes of peak intensity. In order to extract more accurate and reliable Raman information, our group employed the multivariate analysis methods, such as Principle Components Analysis (PCA) and Linear Discriminant Analysis (LDA), to successfully differentiate the blood plasma of nasopharyngeal cancer patients from that of healthy subjects [9]. The Ioan Notingher group also used PCA and LDA methods to distinguish the living tumor cells from normal cells in vitro, and they obtained perfect results too [23].

Paclitaxel, one of the best natural anti-cancer agents extracted from the taxus, is regarded that it can destroy the dynamic equilibrium between the tubulin and tubulin dimmer inside cells, and then, the mitosis will be arrested at the phase of $\mathrm{G}_{2} / \mathrm{M}$ until apoptosis, which achieves the purpose of anti-tumor. Studies had shown that paclitaxel-induced apoptosis is effective in cells of brain cancer, lung cancer, esophageal cancer, melanoma and leukemia tumors [1,2,4,7,8,11,12,14,16,19,22,25-27,29]. So, it is interesting and significant to assess the cytotoxicity of paclitaxel on other tumor cells. Moreover, Burkitt's lymphoma is one of most aggressive malignant lymphoma and probably the fastest growing malignant neoplasm, which seriously harms to human health $[3,18]$.

In this work, the cytotoxicity of paclitaxel for the human Burkitt's lymphoma cells (CA46) is explored based on Raman spectroscopy. We employ the analysis of spectral assignment and the changes of peak intensity combined with PCA and LDA that will be used to analyze and process the Raman spectra obtained from living cells. We try to make it more intuitive, accurate and sensitive to explore the trend of changes of intracellular properties depending on analyzing the cell clusters and calculating the sensitivity and specificity by these multivariate analysis methods.

\section{Material and methods}

\subsection{Major drug reagents and instruments}

Injection paclitaxel $(30 \mathrm{mg} / 5 \mathrm{ml}$ ), fetal calf serum (SH30403 HYCLONE), RPMI-1640 medium (GIBCO), PBS (BOSTER), $\mathrm{CO}_{2}$ humidified incubator (THERMO), confocal micro-Raman spectroscopy (Invia Renishaw). 


\subsection{Cells culture}

The human Burkitt's lymphoma cells (CA46) were supported by Fujian Medical University Union Hospital, cultured at $37^{\circ} \mathrm{C}$ in the $5 \% \mathrm{CO}_{2}$ humidified incubator using a RPMI-1640 medium supplemented with $10 \%$ fetal calf serum. Then, the cells in exponential phase were used as samples.

\subsection{Sample preparation}

Four samples of CA46 were treated with $0.05,0.5,1$ and $5 \mu \mathrm{g} / \mathrm{ml}$ paclitaxel for $24 \mathrm{~h}$, respectively and the control group (control) was supplied with an equal volume of CA46 cells. Before the measurement of Raman spectra, these samples need to be centrifuged (2000 rpm) for $5 \mathrm{~min}$ and washed with PBS twice.

\subsection{Raman spectra and data process}

The Raman spectra were recorded with a confocal Raman micro-spectrometer (Renishaw, UK) in the range of $300-1800 \mathrm{~cm}^{-1}$ under a $785 \mathrm{~nm}$ diode laser excitation. The spectra were collected in backscattering geometry using a microscope equipped with a Leica $50 \times$ objective with a spectral resolution of $2 \mathrm{~cm}^{-1}$; the detection of Raman signal was carried out with a Peltier cooled charge-coupled device (CCD) camera. The software package WIRE 2.0 (Renishaw) was employed for spectral acquisition and analysis. Each Raman spectra were acquired with a $10 \mathrm{~s}$ integration time. 20 cells selected from each sample were measured. All measured Raman spectra were normalized to the integrated area under the curve in the $300-1800 \mathrm{~cm}^{-1}$ wavenumber range after the removal of fluorescence background from the original spectral data. After that, the spectra of the control and treated groups were respectively averaged over 20 cells that were measured, and the normalization whole Raman spectrum data set was fed into the SPSS software package (SPSS Inc., Chicago, IL, USA) for PCA-LDA analysis. Besides, the Raman spectra of different concentrations of paclitaxel also were recorded under the same condition.

\subsection{Statistic analysis}

Principal Component Analysis (PCA) is a multivariate technique used in spectroscopy, which defines a new dimensional space in which the major variance in the original data set can be captured and represented by only a few principal components (PCs) variables. These PCs are used to build a model with a resolution of recognition. In this work, the PCA combined with $T$-test is performed on the spectral data to distinguish control cells and cells treated with different doses of drug (Fig. 3). Linear Discriminant Analysis (LDA) can project the high-dimensional pattern to the best distinction vector space to extract classification information and the compress the dimension of feature space. LDA is a powerful method for extracting the sample feature, maximizing the variance between groups and minimizing the variance within groups according to Fisher's criterion. In this work, the scores of the most significant PCs based on each Raman spectra are used as input to a LDA model to perform the cluster discriminant based on Posteriori Probability (Fig. 4) and determine the sensitivity and specificity of control cells and cells treated with different doses of drug. 


\section{Results and discussion}

\subsection{Analysis of mean spectra}

The mean Raman spectra in the range of $300-1800 \mathrm{~cm}^{-1}$ of CA46 cells (control) and CA46 cells treated with different doses of paclitaxel for $24 \mathrm{~h}$ are shown in Fig. 1(A). All spectra exhibit similar overall features, characterized by Raman peaks based on specific DNA backbone, DNA ring bases and proteins vibrations. The peak assignments $[6,13,21,24]$ of the Raman peaks are given in Table 1. For instance, the strong peak at $1003 \mathrm{~cm}^{-1}$ can be attributed to the phenylalanine. Besides, the changes in the Raman peak intensities located at 831, 1094, 1210, 1257, 1338, 1578 and $1658 \mathrm{~cm}^{-1}$ will be discussed as follows. Figure 1(B) shows the Raman spectra for $5 \mu \mathrm{g} / \mathrm{ml}$ paclitaxel and mean Raman

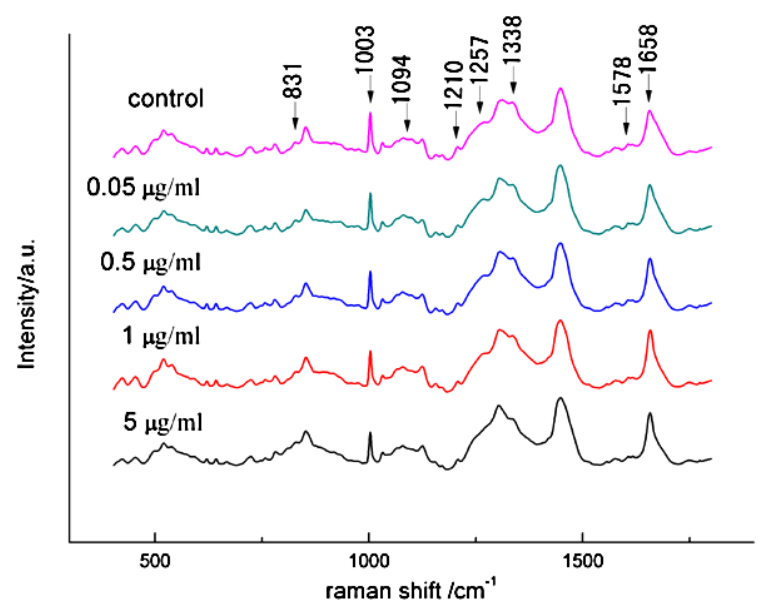

(A)

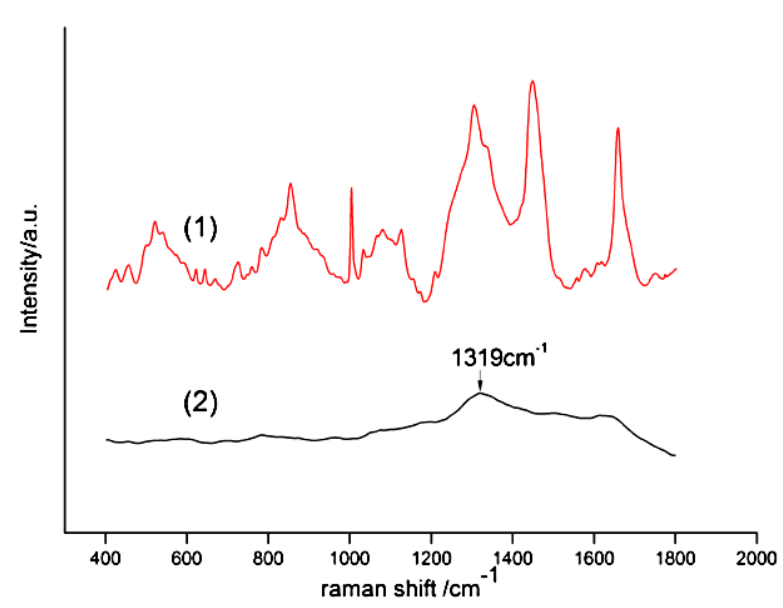

(B)

Fig. 1. (A) Mean Raman spectra for the control CA46 cells (control) and the treated CA46 cells after interacting with paclitaxel of different concentrations for $24 \mathrm{~h}$. (B) Mean Raman spectrum for the CA46 cells after interacting with $5 \mu \mathrm{g} / \mathrm{ml}$ paclitaxel for $24 \mathrm{~h}$ (curve 1) and the background Raman signal of the $5 \mu \mathrm{g} / \mathrm{ml}$ paclitaxel (curve 2). (Colors are visible in the online version of the article; http://dx.doi.org/10.3233/SPE-2011-0497.)

Table 1

The peak positions and assignment of Raman spectra [6,13,21,24]

\begin{tabular}{ll}
\hline Peak positions $\left(\mathrm{cm}^{-1}\right)$ & \multicolumn{1}{c}{ Major assignment } \\
\hline 831 & O-P-O asym. str., Tyr \\
$1003 / 1004$ & Symmetric ring breathing mode of Phe \\
1094 & DNA: O-P-O ${ }^{-}$p: C-N \\
1210 & Tyr and phe v mode \\
1257 & p: Amide III- $\alpha$ \\
1338 & A, G, p: C-H def. \\
1578 & A, G \\
1658 & p: Amide I- $\alpha$ \\
\hline
\end{tabular}

Notes: str. - stretching; def. - deformation vibration; sym. - symmetric; asym. asymmetric; A, G - ring breathing modes of the DNA/RNA bases; $\mathrm{p}$ - protein; Tyr - tyrosine and Phe - phenylalanine. 
spectra for the CA46 cells interacted with $5 \mu \mathrm{g} / \mathrm{ml}$ paclitaxel, respectively. In this study, the Raman spectra of different concentrations of paclitaxel were recorded and it was found that their spectra exhibit same overall features. Here, the contrast between the Raman spectra for $5 \mu \mathrm{g} / \mathrm{ml}$ paclitaxel and mean Raman spectra for the CA46 cells interacted with same does of paclitaxel suggests that the drug hardly has interference signal, which ensures the accuracy of following Raman spectral analysis.

As the concentration of paclitaxel increases, the band at $831 \mathrm{~cm}^{-1}$ assigned to asymmetric stretch of $\mathrm{O}-\mathrm{P}-\mathrm{O}$ in DNA gradually increases in intensity, which indicates the conformation of DNA has been changed possibly. The band at $1094 \mathrm{~cm}^{-1}$ is attributed to the symmetric stretching vibration mode of $\mathrm{PO}_{2}{ }^{-}$in the DNA backbone and it is regarded as an internal intensity standard for the DNA content [15]. The intensity of peak at $1094 \mathrm{~cm}^{-1}$ decreases, however, its position have no change as the concentration of paclitaxel increases, suggesting that changes occur only in the content of DNA rather than the double helix structure of it. Moreover, the peaks at 1338 and $1578 \mathrm{~cm}^{-1}$ due to adenine and guanine of DNA also decrease obviously as the concentration of paclitaxel increases, which illustrates DNA replication has been affected result from the destruction of base pair of DNA.

In addition, the bands at 1210 and $1003 \mathrm{~cm}^{-1}$ due to phenylalanine decrease with the increase in the concentration of agent, which reflects changes in amino-acid residues of protein molecule. Moreover, the bands at 1257 and $1658 \mathrm{~cm}^{-1}$ are characteristic vibration of $\alpha$-helix of Amide III and Amide I, respectively. And their intensity increases after the increase of drug, which indicates the double helix structure of protein has been changed possibly. From the above, those changes will cause disorder for structure of protein. As mentioned before, paclitaxel can destroy the dynamic equilibrium between the tubulin and tubulin-dimer inside cells, and then, the mitosis will be affected at the phase of $\mathrm{G}_{2} / \mathrm{M}$ until apoptosis, which is coincident with the analysis of spectra above.

\subsection{Analysis of mean difference spectra}

Figure 2 illustrates the mean Raman spectra of the CA46 cells treated with different concentrations of agent are directly compared to the control cells to identify the most significant spectral differences with difference spectra. Motivated by this, it is evident that the difference between the cells treated with agent and control cells become greater as the concentration of paclitaxel increases, which indicates there are something abnormal in the structure and content of biochemical molecules inside tumor cells and most of cells come to apoptosis or death with the increase in the concentration of drug. Thus, we conclude that the cytotoxicity of paclitaxel for CA46 is likely related to its concentration, which is coincident with the analysis of spectra above. Besides, it is obvious that there is a strong fluctuation in the difference spectra of control cells and the cells treated with $5 \mu \mathrm{g} / \mathrm{ml}$ paclitaxel, so, the $5 \mu \mathrm{g} / \mathrm{ml}$ of paclitaxel is likely to be as an effective and suitable concentration for damaging the CA46 cells.

\subsection{Analysis of Raman spectra by PCA}

The results of PCA performed on the data sets are shown in Fig. 3, in which the cell clusters standing for control cells and cells treated with $0.05,0.5 \mu \mathrm{g} / \mathrm{ml}$ all overlap and cannot be distinguished by any clear delineation between different groups, which illustrates the difference between control cells and cells treated with $0.05,0.5 \mu \mathrm{g} / \mathrm{ml}$ is unconspicuous, and most of treated cells still have a strong activity because there are few great changes in the structure and content of biochemical molecules. That is to say the cytotoxicity under these two concentrations of drug for the CA46 cells is low. 


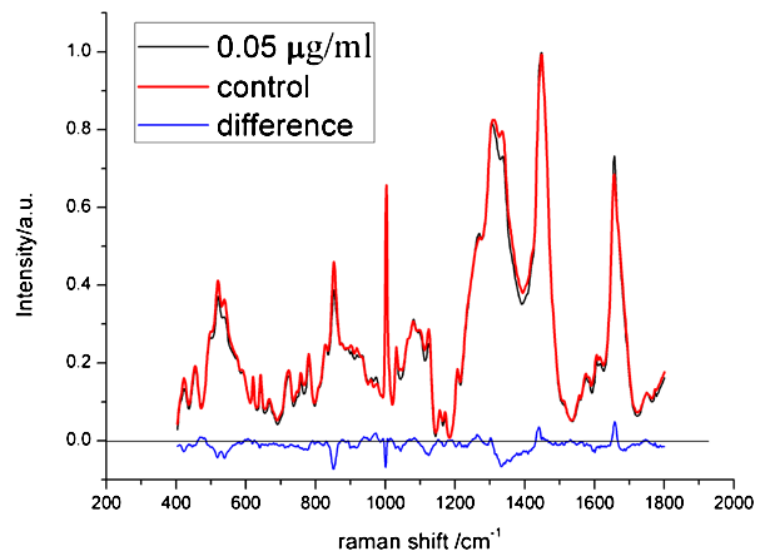

(A)

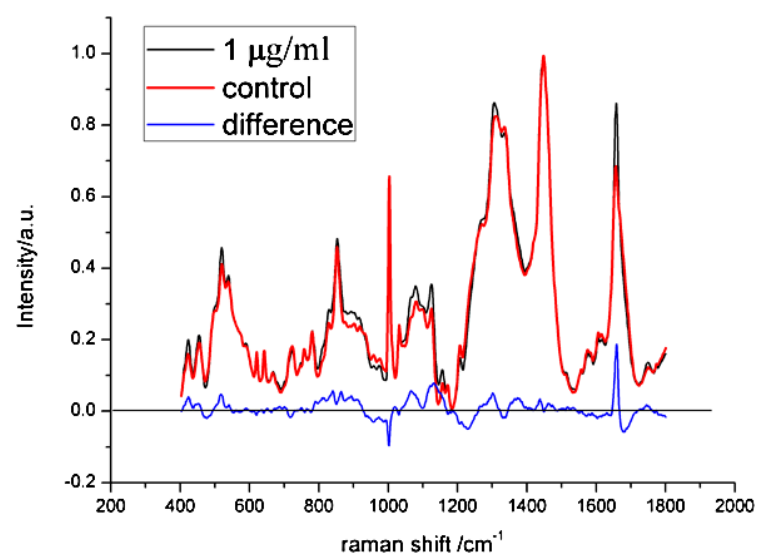

(C)

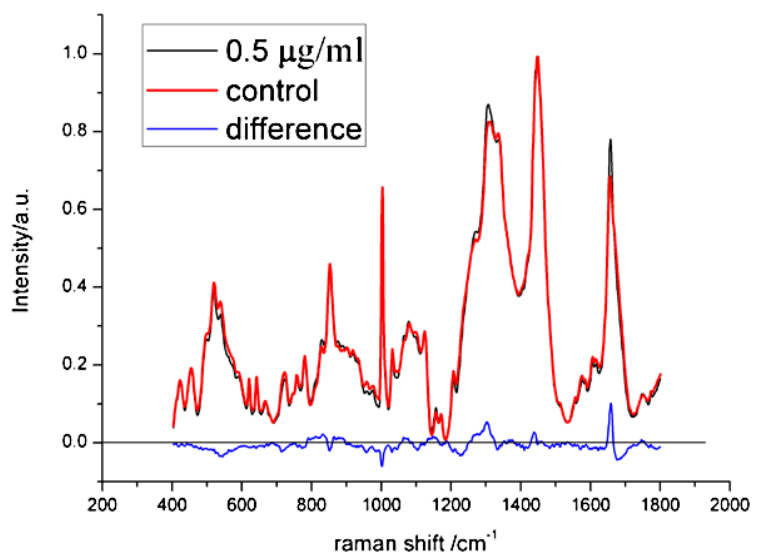

(B)

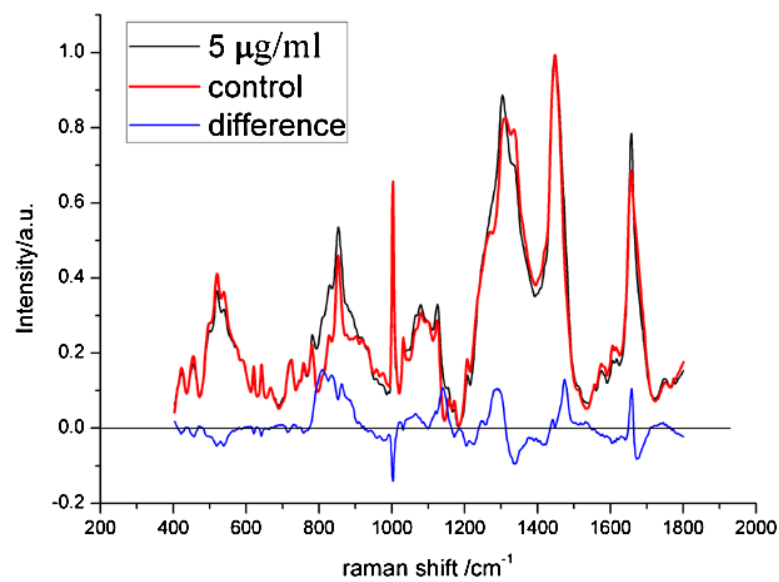

(D)

Fig. 2. Direct comparisons of mean Raman spectra between control cells and the cells treated with (A) $0.05 \mu \mathrm{g} / \mathrm{ml}$, (B) $0.5 \mu \mathrm{g} / \mathrm{ml}$, (C) $1 \mu \mathrm{g} / \mathrm{ml}$ and (D) $5 \mu \mathrm{g} / \mathrm{ml}$ paclitaxel, respectively. Also shown at the bottom of each graph are the difference spectra (blue lines) obtained by subtracting the control spectrum from the treated cell spectrum. (The colors are visible in the online version of the article; http://dx.doi.org/10.3233/SPE-2011-0497.)

In addition, Fig. 3 also shows most of the clusters standing for control cells and cells treated with $1 \mu \mathrm{g} / \mathrm{ml}$ cells have been broadly separated into two parts except the overlap of a few cells, reflecting that variances between control cells and treated cells begin to appear under the concentration of $1 \mu \mathrm{g} / \mathrm{ml}$, and most of cells have been damaged. Moreover, the trend of separation between different cell clusters is more obvious under the concentration of $5 \mu \mathrm{g} / \mathrm{ml}$. The control cells and cells treated with $5 \mu \mathrm{g} / \mathrm{ml}$ have formed distinct, separate groups absolutely in this case, and the resolution ratio reaches to $100 \%$. So, it can be concluded that almost all of the CA46 cells have been damaged or induced to apoptosis with the concentration of $5 \mu \mathrm{g} / \mathrm{ml}$.

Besides, from the analysis above, we also find that the variance of control cells and cells treated with drug become greater gradually as the concentration of paclitaxel increases, which is coincident with the analysis of spectra before. Motivated by this, the strong evidence of statistics for the research has been supported by PCA. 


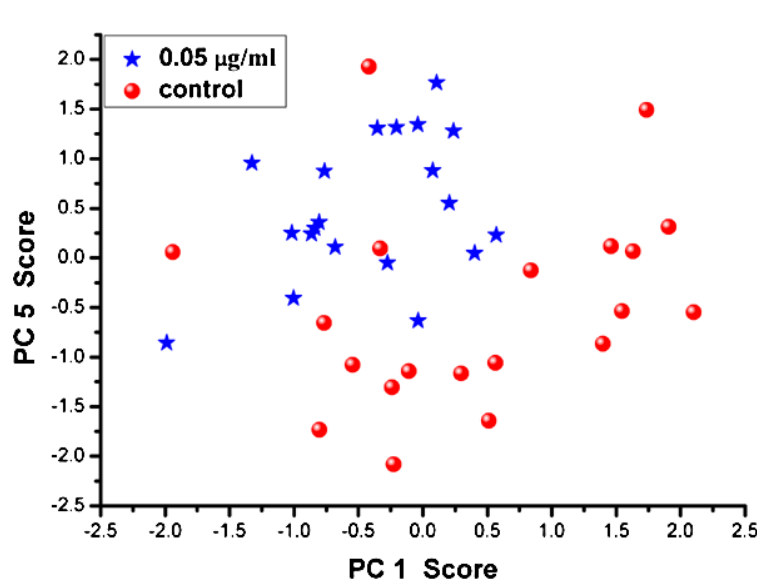

(A)

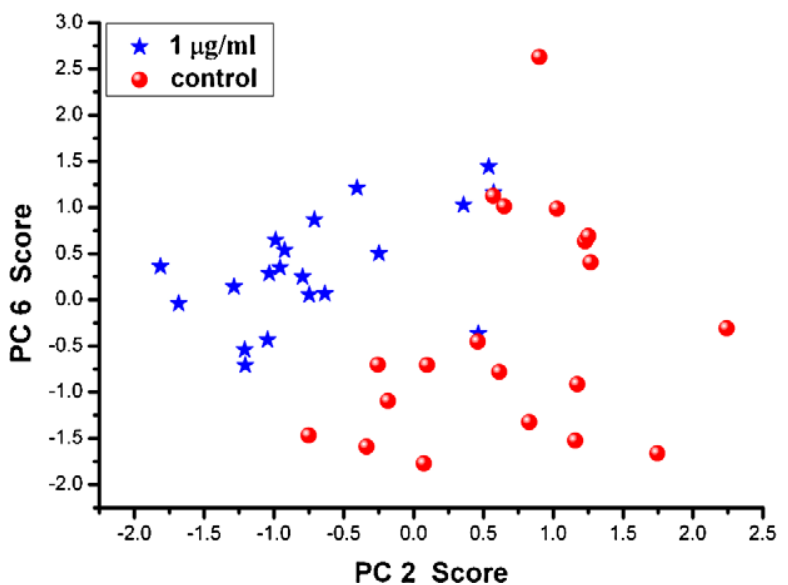

(C)

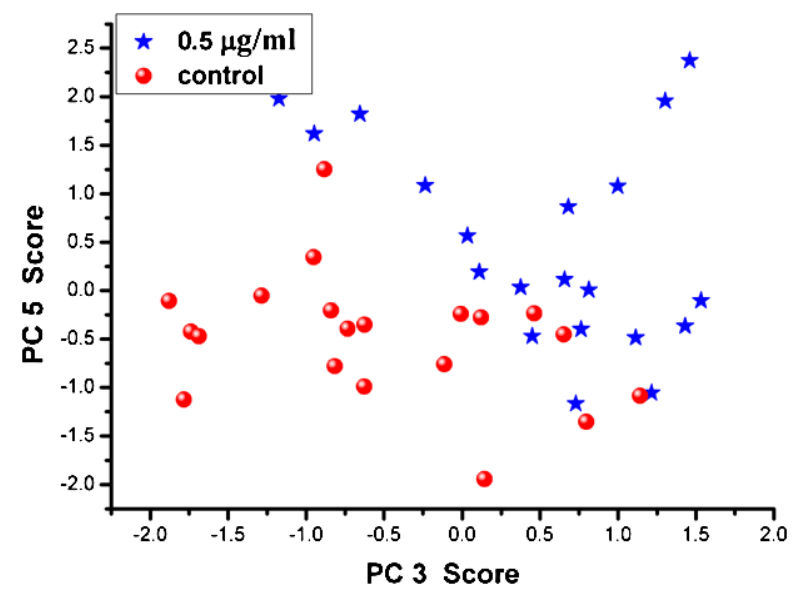

(B)

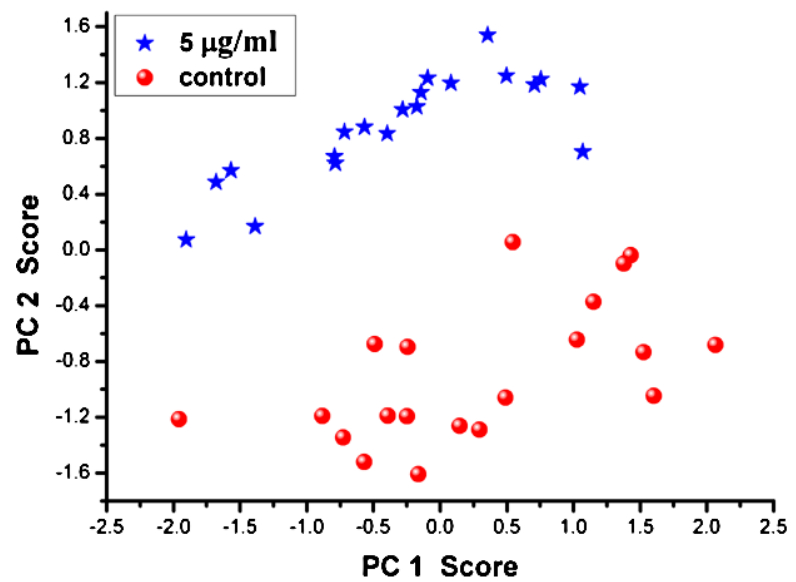

(D)

Fig. 3. PCA scatter plots comparing control cells and the cells treated with (A) $0.05 \mu \mathrm{g} / \mathrm{ml}$, (B) $0.5 \mu \mathrm{g} / \mathrm{ml}$, (C) $1 \mu \mathrm{g} / \mathrm{ml}$ and (D) $5 \mu \mathrm{g} / \mathrm{ml}$ drug doses. (Colors are visible in the online version of the article; http://dx.doi.org/10.3233/SPE-2011-0497.)

\subsection{Analysis of Raman spectra by LDA}

Figure 4 shows the posterior probability provided by LDA of control CA46 cells and the cells treated with $0.05,0.5,1,5 \mu \mathrm{g} / \mathrm{ml}$, based on their Raman spectra. It is found that the cluster points of control cells and cells treated with different doses of drug constantly gather to their respective ends, as the concentration of drug increases. This illustrates that the variance between groups is getting larger, meanwhile, the variance within groups is becoming smaller. In addition, the cells treated with 1 and $5 \mu \mathrm{g} / \mathrm{ml}$ drug can be easily distinguished from the control cells by LDA method. Furthermore, when the drug dose reaches to $5 \mu \mathrm{g} / \mathrm{ml}$, the largest between-class scatter and smallest within-class scatter appear between control cells and treated cells. It is clear that the changes of intracellular properties become bigger with the increase in the dose of drug, which indicates the cytotoxicity of paclitaxel for the CA46 is getting stronger. Besides, the specificity of control CA46 cells and the cells treated with $0.05,0.5,1$ and $5 \mu \mathrm{g} / \mathrm{ml}$ respectively is $75,85,95$ and $100 \%$, and the sensitivity for all these cases is $100 \%$. This is consistent with the clustering trend shown by Fig. 4. Through the LDA's discriminant analysis, it is again confirmed that there 


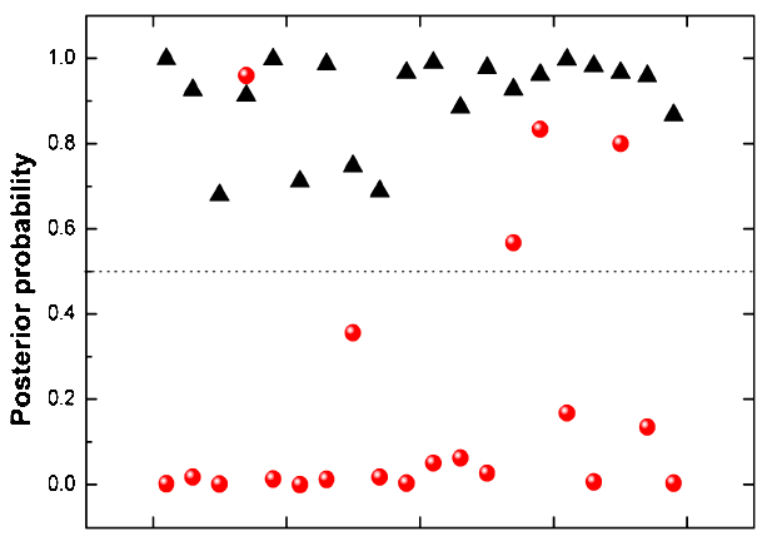

(A)

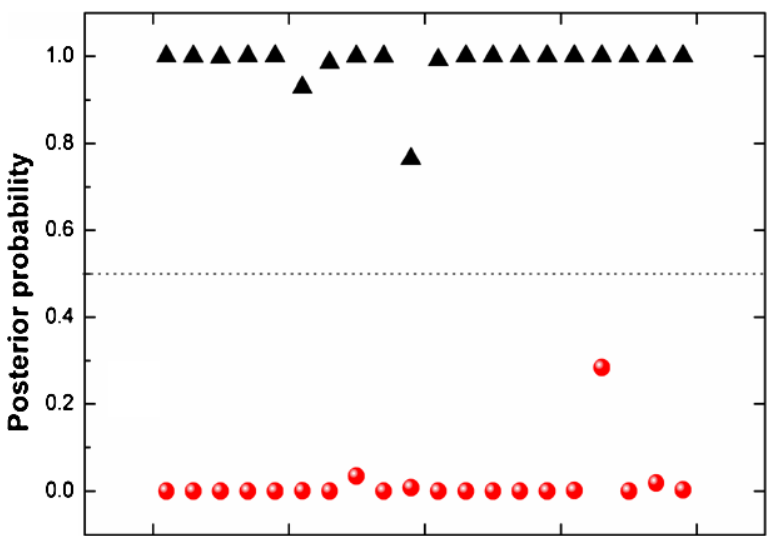

(C)

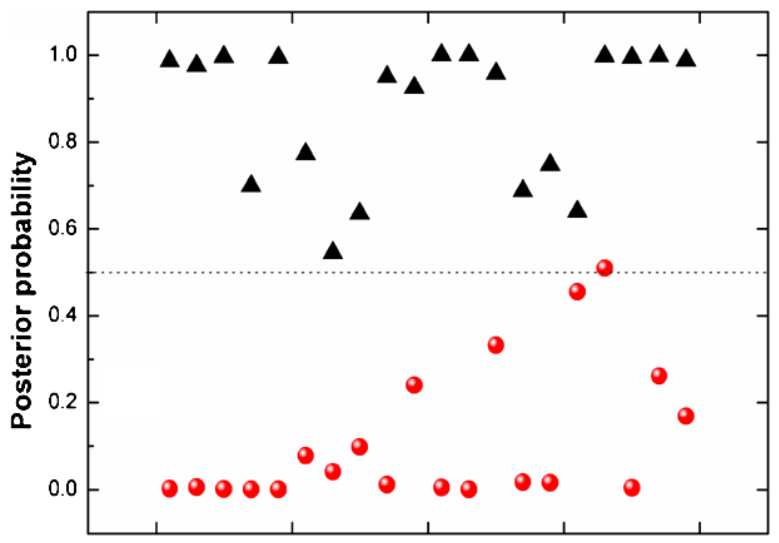

(B)

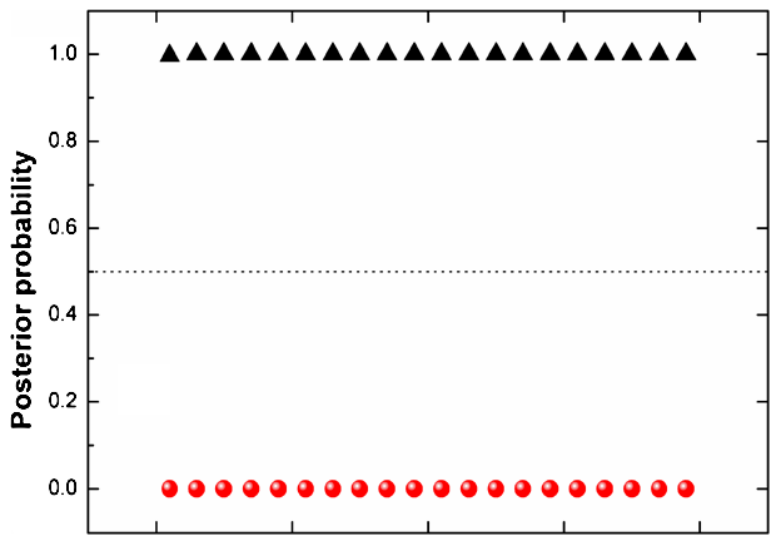

(D)

Fig. 4. LDA scatter plots comparing control cells and the cells treated with (A) $0.05 \mu \mathrm{g} / \mathrm{ml}$, (B) $0.5 \mu \mathrm{g} / \mathrm{ml}$, (C) $1 \mu \mathrm{g} / \mathrm{ml}$ and (D) $5 \mu \mathrm{g} / \mathrm{ml}$ drug, based on the posterior probability $(-$ control group of CA46 cells; $\boldsymbol{\Lambda}$ - treated group of CA46 cells with different doses of drug). (Colors are visible in the online version of the article; http://dx.doi.org/10.3233/SPE-2011-0497.)

is concentration-dependent in the process of paclitaxel for the CA46 cells. Moreover, we believe that $5 \mu \mathrm{g} / \mathrm{ml}$ is optimal dose of paclitaxel for the CA46 cells.

\section{Conclusion}

In this paper, Raman spectroscopy combined with multivariate analysis methods was used to study the interactional efficacy of human Burkitt's lymphoma cells (CA46) in vitro with paclitaxel. Raman spectra were successfully obtained from individual CA46 cells treated with different doses of paclitaxel to detect the structure and content changes of biochemical molecules. Specific biomolecular differences observed include the change in protein structure and the decrease in the cellular DNA concentration, as the concentration of paclitaxel increases, depending on the analysis of spectral assignment and the changes of peak intensity. Besides, the multivariate methods, such as PCA and LDA, can be employed to build high accuracy models to discriminate between control CA46 cells and the cells treated with different doses of paclitaxel, which showed that the specificity of control CA46 cells and the cells treated 
with $0.05,0.5,1$ and $5 \mu \mathrm{g} / \mathrm{ml}$ respectively is $75,85,95$ and $100 \%$, and the sensitivity for all these cases is $100 \%$. This demonstrates that the variances of control cells and cells treated with drug become greater gradually as the concentration of paclitaxel increases. It is obvious that these multivariate methods can enhance the advantages of Raman spectroscopy study in individual living cells. These results suggest that the cytotoxicity of paclitaxel for the CA46 would increase gradually as the increase in the dose of drug, and $5 \mu \mathrm{g} / \mathrm{ml}$ of paclitaxel is likely to be as an effective and suitable concentration for damaging the CA46 cells. This study also indicates that Raman spectroscopy combined with multivariate analysis methods could become a non-destructive real-time tool for in vitro studying the paclitaxel effect for human Burkitt's lymphoma cells.

\section{Acknowledgements}

This work was supported by the National Natural Science Foundation of China (Nos 60778046 and 60910106016), the Science and Technology Project of Fujian Province (Nos 2008J0016 and 2009J01276), the Project of Science Foundation of Ministry of Health and United Fujian Provincial Health and Education Project for Tackling the Key Research (No. WKJ2008-2-046) and the Canadian Institutes of Health Research International Scientific Exchange Program.

\section{References}

[1] N. Aissat, C. Le Tourneau, A. Ghoul, M. Serova, I. Bieche, F. Lokiec, E. Raymond and S. Faivre, Antiproliferative effects of rapamycin as a single agent and in combination with carboplatin and paclitaxel in head and neck cancer cell lines, Cancer Chemoth. Pharm. 62 (2008), 305-313.

[2] J. Alexandre, F. Batteux, C. Nicco, C. Chéreau, A. Laurent, L. Guillevin, B. Weill and F. Goldwasser, Accumulation of hydrogen peroxide is an early and crucial step for paclitaxel-induced cancer cell death both in vitro and in vivo, Int. J. Cancer 119 (2006), 41-48.

[3] V. Banthia, A. Jen and A. Kacker, Sporadic Burkitt's lymphoma of the head and neck in the pediatric population, Int. J. Pediatr. Otorhi. 67 (2003), 59-65.

[4] K. Bhalla, A. Ibrado, E. Tourkina, C. Tang, M. Mahoney and Y. Huang, Taxol induces internucleosomal DNA fragmentation associated with programmed cell death in human myeloid leukemia cells, Leukemia 7 (1993), 563.

[5] J. Chan, D. Taylor, S. Lane, T. Zwerdling, J. Tuscano and T. Huser, Nondestructive identification of individual leukemia cells by laser trapping Raman spectroscopy, Anal. Chem. 80 (2008), 2180-2187.

[6] J. Chan, D. Taylor, T. Zwerdling, S. Lane, K. Ihara and T. Huser, Micro-Raman spectroscopy detects individual neoplastic and normal hematopoietic cells, Biophys. J. 90 (2006), 648-656.

[7] Y. Chang, L. Li, C. Wu, T. Liu, W. Lui, F. P'eng and C. Chi, Paclitaxel-induced apoptosis in human gastric carcinoma cell lines, Cancer 77 (1996), 14-18.

[8] F. Fallo, C. Pilon, L. Barzon, M. Pistorello, U. Fagotto, G. Altavilla, M. Boscaro and N. Sonino, Effects of taxol on the human NCI-H295 adrenocortical carcinoma cell line, Endocr. Res. 22 (1996), 709-715.

[9] S. Feng, R. Chen, J. Lin, J. Pan, G. Chen, Y. Li, M. Cheng, Z. Huang, J. Chen and H. Zeng, Nasopharyngeal cancer detection based on blood plasma surface-enhanced Raman spectroscopy and multivariate analysis, Biosens. Bioelectron. 25 (2010), 2414-2419.

[10] S. Feng, J. Lin, M. Cheng, Y. Li, G. Chen, Z. Huang, Y. Yu, R. Chen and H. Zeng, Gold nanoparticle based surfaceenhanced Raman scattering spectroscopy of cancerous and normal nasopharyngeal tissues under near-infrared laser excitation, Appl. Spectrosc. 63 (2009), 1089-1094.

[11] Y. Gan, M. Wientjes, D. Schuller and J. Au, Pharmacodynamics of taxol in human head and neck tumors, Cancer Res. 56 (1996), 2086.

[12] E. Goldblatt, E. Gentry, M. Fox, S. Gryaznov, C. Shen and B. Herbert, The telomerase template antagonist GRN163L alters MDA-MB-231 breast cancer cell morphology, inhibits growth, and augments the effects of paclitaxel, Mol. Cancer Ther. 8 (2009), 2027.

[13] H. Gremiich and B. Yan, Infrared and Raman Spectroscopy of Biological Materials, M. Dekker, New York, 2000. 
[14] L. Havrilesky, A. Elbendary, J. Hurteau, R. Whitaker, G. Rodriguez and A. Berchuck, Chemotherapy-induced apoptosis in epithelial ovarian cancers, Obstet. Gynecol. 85 (1995), 1007-1010.

[15] S. Hawi, W. Campbell, A. Kajdacsy-Balla, R. Murphy, F. Adar and K. Nithipatikom, Characterization of normal and malignant human hepatocytes by Raman microspectroscopy, Cancer Lett. 110 (1996), 35-40.

[16] D. Henley, M. Isbill, R. Fernando, J. Foster and J. Wimalasena, Paclitaxel induced apoptosis in breast cancer cells requires cell cycle transit but not Cdc2 activity, Cancer Chemoth. Pharm. 59 (2007), 235-249.

[17] Z. Huang, A. McWilliams, H. Lui, D. McLean, S. Lam and H. Zeng, Near-infrared Raman spectroscopy for optical diagnosis of lung cancer, Int. J. Cancer 107 (2003), 1047-1052.

[18] A. Jan, K. Vora and G. Sandor, Sporadic Burkitt's lymphoma of the jaws: the essentials of prompt life-saving referral and management, J. Can. Dent. Assoc. 71 (2005), 165-168.

[19] X. Li, J. Gong, E. Feldman, K. Seiter, F. Traganos and Z. Darzynkiewicz, Apoptotic cell death during treatment of leukemias, Leukemia and Lymphoma 13 (1994), 65-70.

[20] J. Lin, R. Chen, S. Feng, Y. Li, Z. Huang, S. Xie, Y. Yu, M. Cheng and H. Zeng, Rapid delivery of silver nanoparticles into living cells by electroporation for surface-enhanced Raman spectroscopy, Biosens. Bioelectron. 25 (2009), 388-394.

[21] A. Mahadevan-Jansen and R. Richards-Kortum, Raman spectroscopy for the detection of cancers and precancers, J. Biomed. Opt. 1 (1996), 31-70.

[22] C. Milross, K. Mason, N. Hunter, W. Chung, L. Peters and L. Milas, Relationship of mitotic arrest and apoptosis to antitumor effect of paclitaxel, J. Natl. Cancer Inst. 88 (1996), 1308.

[23] I. Notingher, G. Jell, P. Notingher, I. Bisson, O. Tsigkou, J. Polak, M. Stevens and L. Hench, Multivariate analysis of Raman spectra for in vitro non-invasive studies of living cells, J. Mol. Struct. 744 (2005), 179-185.

[24] I. Notingher, S. Verrier, H. Romanskab, A. Bishopb, J. Polak and L. Hench, In situ characterisation of living cells by Raman spectroscopy, Spectroscopy 16 (2002), 43-51.

[25] E. Rowinsky and R. Donehower, Antimicrotubule agents, in: Cancer: Principles and Practice of Oncology, 6th edn, Lippincott Williams \& Wilkins, Philadelphia, PA, 2001, pp. 431-447.

[26] A. Terzis, F. Thorsen, O. Heese, T. Visted, R. Bjerkvig, O. Dahl, H. Arnold and G. Gundersen, Proliferation, migration and invasion of human glioma cells exposed to paclitaxel (Taxol) in vitro, Brit. J. Cancer 75 (1997), 1744.

[27] Z. Wang, K. Butt, L. Wang and H. Liu, The effect of seal oil on paclitaxel induced cytotoxicity and apoptosis in breast carcinoma MCF-7 and MDA-MB-231 cell lines, Nutr. Cancer 58 (2007), 230-238.

[28] H. Yao, Z. Tao, M. Ai, L. Peng, G. Wang, B. He and Y. Li, Raman spectroscopic analysis of apoptosis of single human gastric cancer cells, Vib. Spectrosc. 50 (2009), 193-197.

[29] W. Yen, M. Wientjes and J. Au, Differential effect of taxol in rat primary and metastatic prostate tumors: Site-dependent pharmacodynamics, Pharm. Res. 13 (1996), 1305-1312. 


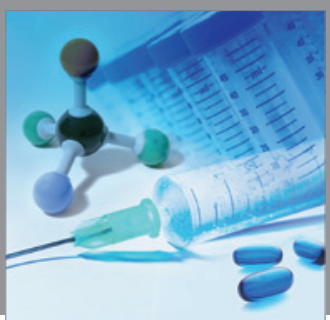

International Journal of

Medicinal Chemistry

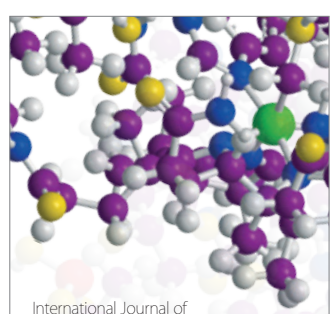

Carbohydrate Chemistry

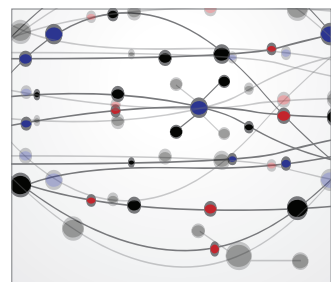

The Scientific World Journal
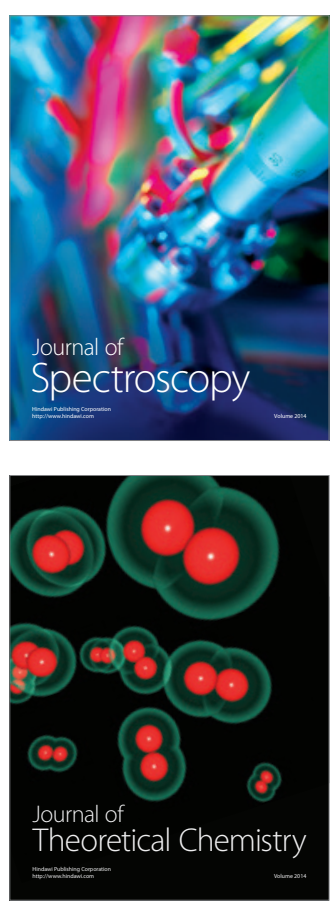
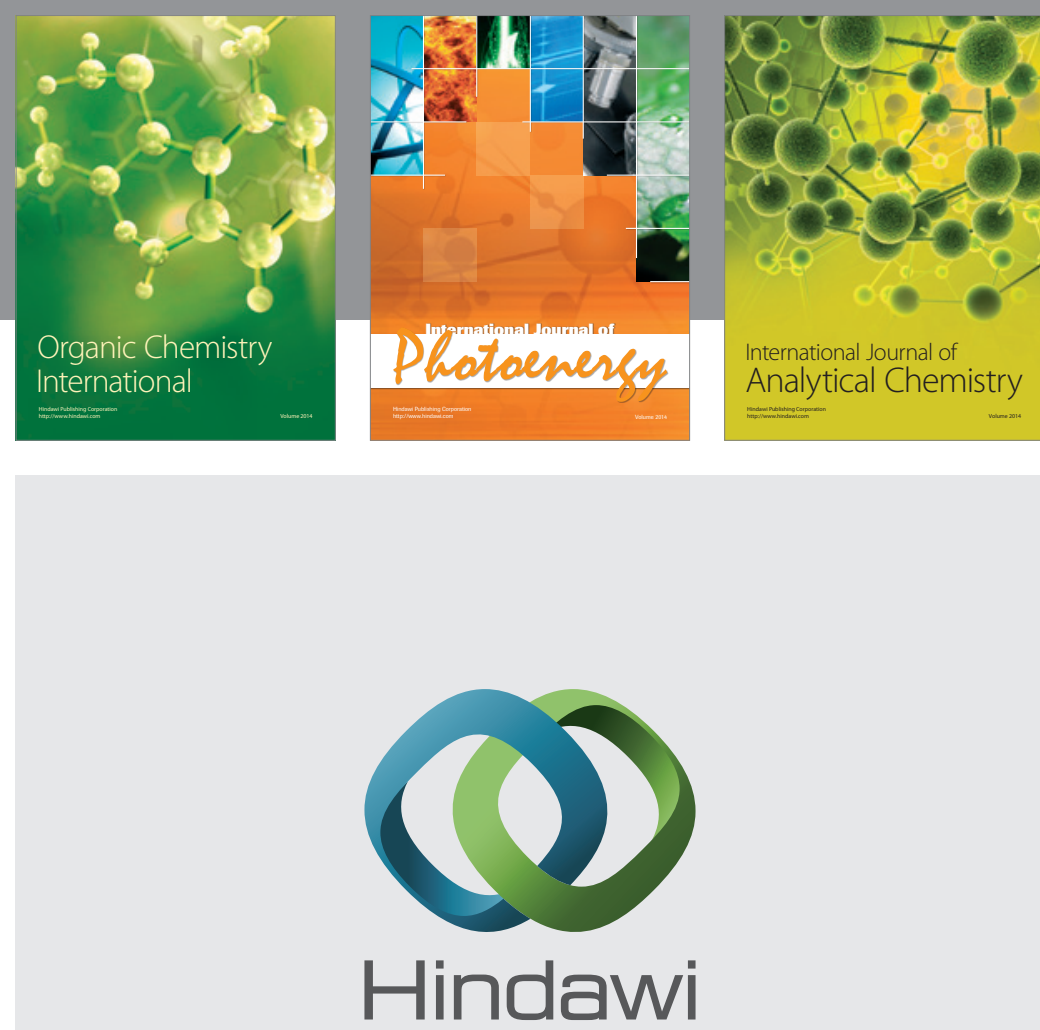

Submit your manuscripts at

http://www.hindawi.com
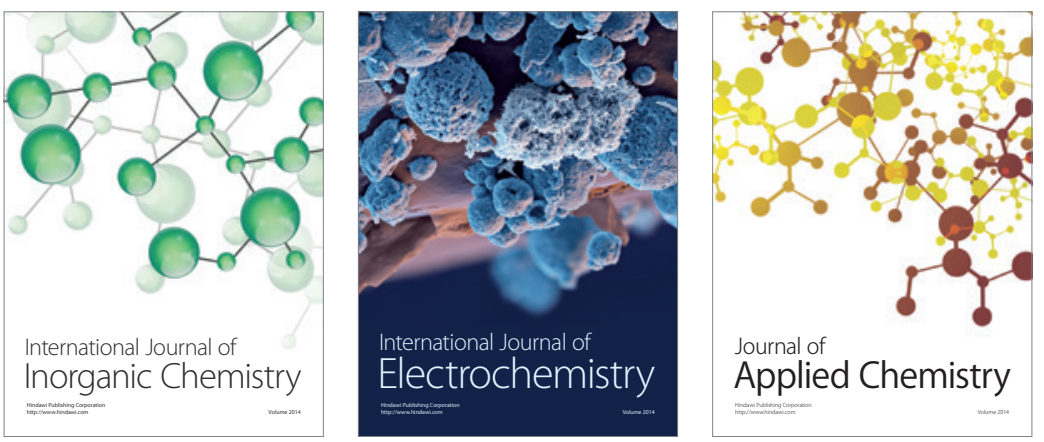

Journal of

Applied Chemistry
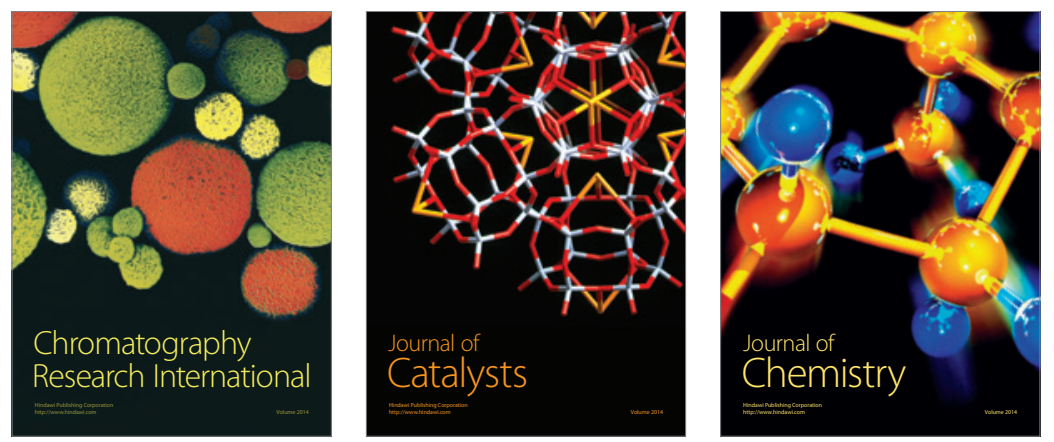
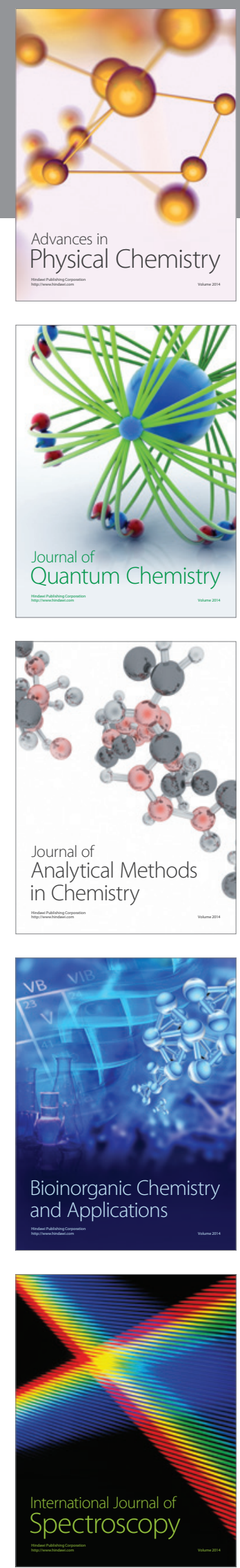